\title{
Comparative Evaluation of Geotechnical Properties of Red Tropical Soils and Anthills from parts of Edo State for Road Construction
}

\section{*11ANDRE-OBAYANJU, O; ${ }^{2}$ IMARHIAGBE, OJ; ${ }^{3}$ ONYEOBI, TUS}

\author{
${ }^{1,2,3}$ Department of Geology, University of Benin, Benin City, Edo State, Nigeria \\ ${ }^{* 1}$ omodre@yahoo.com, ${ }^{2}$ osayamen.imarhiagbe@physci.uniben.edu, 3 tuso54@yahoo.com \\ Corresponding Author: Tel. +234 8056106792
}

\begin{abstract}
Geotechnical tests were carried out on a total of six samples of red tropical soils developed over sedimentary and Basement terrains, made up of three soils and three termite hills samples. The soil samples were subjected to geotechnical analyses which included the Particle size analysis, Specific Gravity, Atterberg Limits and Compaction Test to evaluate their suitability for road construction. The results from the analyses showed that soils were well graded(GW) with percentage fines ranging from 28.06 to $57.8 \%$, Specific Gravity ranged from 2.40-2.60, Liquid Limit from 36-48.5\% , Plastic Limit ranged from 19-30\%, Plasticity Index 15-19\% and California Bearing Ratio(unsoaked) from 11-24\%. For the termite soils Liquid Limit varies from 26.5-33\%, Plastic Limit 19-23\%, Plasticity Index 10-12\% and California Bearing Ratio 24-40\%. The Compaction Test results showed that the Maximum Dry Density (MDD) ranged from 1.44 to $1.65 \%, 1.6-1.8 \%$ and Optimum Moisture Content from 16.3 to $23.8 \%$ and 12.5 to $17.8 \%$ for soils and termite hill respectively. From the results of the analyses and in accordance with the Federal Ministry of Works and Housing, recommendations for road base, subbase and subgrade, both soils can be used for road construction as subgrade but the termite hill of Igarra indicate a better material because of its higher strength with higher MDD to low moisture content.
\end{abstract}

DOI: https://dx.doi.org/10.4314/jasem.v21i7.4

Copyright (C) 2017 Andre-Obayanje et al. This is an open access article distributed under the Creative Commons Attribution License (CCL), which permits unrestricted use, distribution, and reproduction in any medium, provided the original work is properly cited

Received 5 May 2017; received in revised form 10 September 2017; accepted 09 December 2017

Keywords: Red tropical soils, Geotechnical, termite hills, subgrade, suitability, construction.

A considerable increase in soil utility for engineering works is expected as any country aspires towards improved infrastructural development. The relationship between all engineering infrastructure and their foundation soils is of paramount importance for designers and contractors. Incessant occurrence of road pavement deterioration and building collapse, mainly because of their poor geotechnical and mechanical properties has made it imperative for a proper understanding of the geotechnical properties of soils (Garg, 2009). As far back as the eighteenth century, geologists identified that in warm, moist, temperate and tropical climates, water percolating through rock has a strong weathering action (Millard, 1993).

Despite the great effort that has been made by previous works to classify and differentiate tropical soils, a uniform nomenclature /classification system does not exist yet for these soils. Hence, the term "lateritic clays", "lateritic gravels" and even "laterites" are still used by engineers to describe any reddish tropical soils, Northmore et al, (1996). Fortunately, for the engineering purposes it does not matter whether the classification is correct, but that the geological and engineering properties as predicted or derived from testing are reliable. The soils used in road construction in West Africa are mostly residual red tropical soils which contribute to the general economy of the region where they are found Lemoguna et al, (2011).

Residual soils (red tropical soils) are formed in situ by chemical weathering and may be found on rock level surfaces where action of elements has produced a soil with little tendency to move i.e. it holds the position of their formation without transporting, just above the parent rock. An essential feature for the formation of red tropical soil is the repetition of wet and dry seasons. Rocks are leached by percolating rain water during wet season resulting in solutions containing leached anions which are brought to the surface by capillary action during the dry season (Vamaguche, 2003). Ferruginous and aluminous clay soils are frequent products of weathering in tropical latitudes (Anon, 1990a). They are characterized by the presence of iron and aluminium oxides and hydroxides. Red tropical soil is a residual ferruginous clay-like deposit which generally occurs below a hardened ferruginous crust or hardpan.

Geotechnical characteristics and field performance of red tropical soil may be interpreted in the light of all or some of the following parameters even their reaction to different stabilizing agents i.e. Genesis and pedological factors (parent material, climate, 
topography, vegetation, period of time in which the processes have operated), degree of weathering (decomposition, sesquioxides enrichment and claysize content, degree of leaching), Position in the topographic site, and depth of soil in the profile (Gidigasu, 1976). A comparative evaluation of the geotechnical properties of some red tropical soils and anthills from Igarra and Benin, Southwest Nigeria was carried out by determining the individual strength of the soil and anthill using the basic geotechnical tests (particle size analyses, specific gravity tests, Atterberg tests and compaction tests), comparing the results with available standards in order to know if the soil strength meet the requirements for engineering road constructions or the soils would require stabilization and to increase knowledge base on termite hill technology in road material improvement.

\section{MATERIALS AND METHODS}

The Study Area: The study samples were collected from Akoko Edo and Ovia North east area in Edo state. Two samples each of red tropical soils and anthills along the Igarra- Ibillo road and one sample each of red tropical soil and anthill from Benin were collected at the following location points

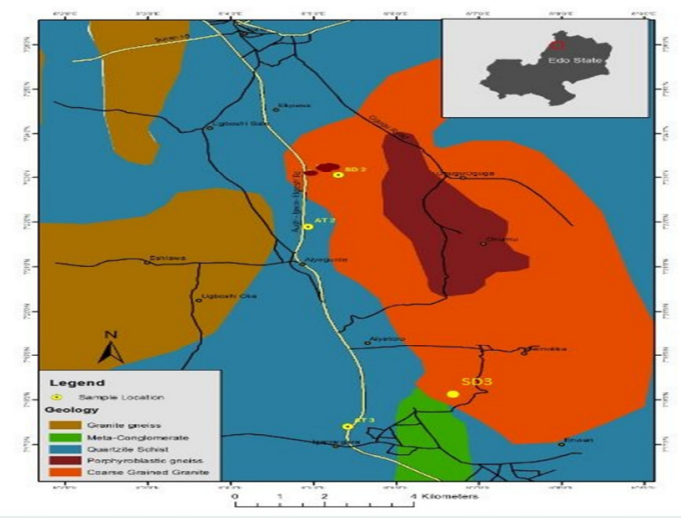

Fig 1: Map showing sampled areas in Igarra and Ibillo

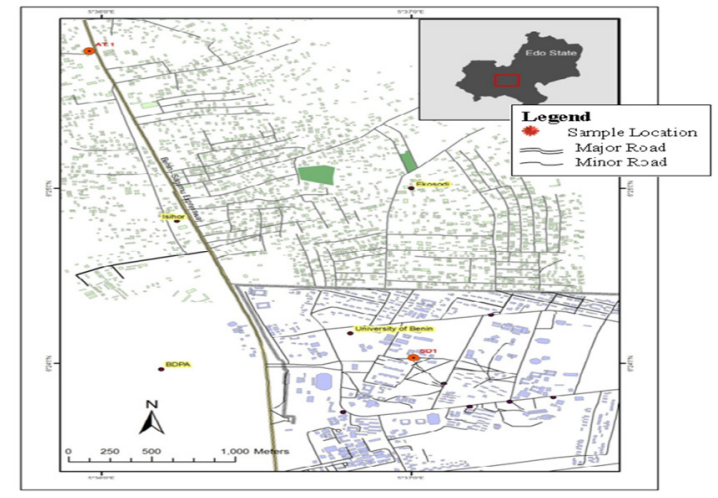

Fig 2: Map of sampled area in Benin
The Benin Region is underlain by sedimentary formation of the Niger Delta Basin. The geology of the region is under continuous and intense physicochemical transformation. It is generally marked by top Red Tropical Soils composed of low silicasesquioxide ratio clay sand which is soft when wet and considerably hard when dry Alayaki et al, (2015). The term Benin sand was first used by Parkinson (1907), to describe the Red Tropical Soils underlain by sands, sandy clays and ferruginous sandstone that mark the Paleo-Coastal Environment of Paleocene-Pleistocene Age. These sediments spread across the southern fringes of the Anambra Basin and mark the upper fancies off-flaps of the Niger Delta. Tattam (1943), used the name Coastal plain sands to describe the formation of Red Tropical Soils underlain by sands and clays that mark an ancient coastal plain environment now exposed in Calabar, Owerri, Onitsha and the Benin Region with the age Oligocene-Pleistocene. However, Reyment (1965), reinstated the name Benin Formation to identify the reddish-brown-yellow, generally white sands often with clayey and pebbly horizons with type-locality around Benin. The lithostratigraphy of the Benin Formation (Miocene- Recent) is characterized by $90 \%$ sand, conglomeratic gravels (pebbles and cobbles), clays, peat and lignite (infrequent; occurring as beds or dispersed fragments) deposited in a continental coastal plain (fluvial) depositional setting (Nwajide, 2013).

Igarra and Ibillo area is underlain by the rocks of the Precambrian basement complex of Nigeria. According to Ajibade (1976), the rocks can be grouped into a simplified three (3) fold subdivision: the migmatite gneiss complex, the monocyclic younger metasediments and the older granites. The migmatite gneiss complex makes up about $30 \%$ of the Nigerian basement. The rocks of the complex are polycyclic (i.e. have a polymetamorphic history), ranging from Leonian to Pan-African ages (Rahaman, 1976; Ajibade et al 1987) and can be subdivided into three (5) sub-groups: gneisses (which can be further subdivided into early gneiss, mafic-ultramafic components and granitic (felsic), Quartzite (massive, schistose and pseudo-conglomeratic), marbles and calc-silicate rocks. The rocks belonging to the monocyclic Younger metasediments group underlie most of the Akoko-Edo area (especially the southern part). These rocks are known here as rocks of the Igarra schist belt, comprising metaconglomerates, quartzites, quartz mica schists, marbles and calcsilicate rocks (Odeyemi, 1988). In comparison with similar rocks in other parts of Nigeria, these rocks have been assigned Pan-African ages. 
Sample Collection: Field work was conducted using traverse method to access sample locations. A total of six (6) samples were collected comprising three (3) laterites soils and three (3) termite hills form three different locations. The soils were gotten from between $1 \mathrm{~m}$ to $3.5 \mathrm{~m}$ in depth and each soil sample collected was observed in hand specimen and later stored in separate polythene bags and labeled accordingly for easy identification. The samples collected were sent to the Laboratory for the following analyses. Sieve analysis (particle size), Atterberg limits test, Bulk and dry density, soil compaction test and specific gravity test.

Sample Analysis: Particle-size analysis was done with a combination of wet sieving and hydrometer method. The sieves were arranged in order of reducing aperture. (100g each of the soil samples was used throughout the analysis).The set of sieves were placed on the mechanical shaker accompanied by a jarring action for 5 minutes for proper sieving of the soil sample. The mass of soil sample retained on each sieve was recorded against the sieve aperture size on a semi-log graph together with percentage fines (known as particle size distribution curve). The general slope has the shape of the distribution and it is described by means of some constants such as effective sizes $\mathrm{D}_{10}$, coefficient of uniformity $(\mathrm{Cu})$ and coefficient of curvature $(C c)$ which was calculated to determine the grading of soil. For a material to be well graded it must fulfill one or all of the following: the $C c$ is between 1.0 and 3.0; and or $C u$ must be greater than 5.0. Otherwise it is poorly graded.

The moisture content test was used to determine the water content of the soil. It is expressed as a percentage of the weight of water to the dry weight of the soil. A known weight of sample about 50grams was taken out of the preserved samples from the field and weighed. The sample was oven dried at a temperature of about $110^{\circ} \mathrm{C}$ for about 24 hours

Specific gravity is the ratio of the weight of a substance to that of an equal volume of water. The specific gravity is dimensionless. The specific gravity for water is 1. Apparatus used are conical flask, distilled water and measuring scale Soil sample which was air-dry weighed $150 \mathrm{~g}$ after which it was filled with distilled water. The pycnometer with the water was weighed and then bottle was then emptied and dried. The oven dry samples was introduced into the bottle, the soil was stirred with a glass rod in order to allow trapped air to be released. Sufficient air-free distilled water was added so that the soil in the bottle is just covered then weighed. The specific gravity is the ratio of the unit weight of soil particles to the unit weight of water at some known temperature (usually 400C). The specific gravity of soil is generally between 2.50 and 2.90 for sand is 2.63 ; silt is 2.70 and 2.90 .

The Atterberg Limit test, also known as the Consistency Limit Test is used to determine the effect of moisture content on fine grained soil. It defines the boundaries of several state of consistency of plastic soil. It is used to determine the plasticity of soil. Liquid limit, plastic limit, plasticity index, liquidity index and relative consistency are some parameters determined through Atterberg limit. These parameters help to determine the plasticity and clay content of a soil sample. The liquid limit test was carried out using the Cassagrande method.

Compaction tests are carried out with the aim of determining the moisture density relationships and change in soils, increase unit weight, shear strength, reducing permeability. This makes the soil less susceptible to settlement under load, especially repeated loading. A number of methods have been developed for this purpose. These include the standard compaction method (also called proctor method), the modified (The American Association of State Highway and Transportation Officials) AASHTO method and the vibrating hammer methods. This is usually done by mechanical means. $2.5 \mathrm{~kg}$ method of compaction was used for this test. The apparatus consist of $2.5 \mathrm{~kg}$ rammer, a known volume of mould with removable base and a detachable collar. Three kilogram of air dried soil was used for the test and the test was repeated five times for each sample. The moisture content used was between $4 \%-20 \%$ of the weight of the sample, and samples were mixed thoroughly before compaction. Three layers of compaction were done for each trial and 25 blows were used to compact each layer. Graphs of dry density, $\rho_{d}$ against moisture content were plotted to determine the optimum moisture content.

These analyses were carried out at the Civil Engineering Department Laboratory of University of Benin, Benin-City in accordance with B.S. 1377. (1975). Compaction was done with the West African standard.

\section{RESULTS AND DISCUSSION}

The Soil fraction Proportions show percentages of sand, silt, clay in each sample were obtained from the Particle size distribution and presented in Table 1 The Soil Grading parameters Coefficient of Uniformity $(\mathrm{Cu})$ and Coefficient of curvature $(\mathrm{Cc})$, used in evaluating the grading of the soil samples as 
calculated from the particle size distribution curves as presented in Table 2. For a well graded soil $\mathrm{Cu}>5,1 \leq$ $\mathrm{Cc} \leq 3$, if these criteria are not met then its poorly

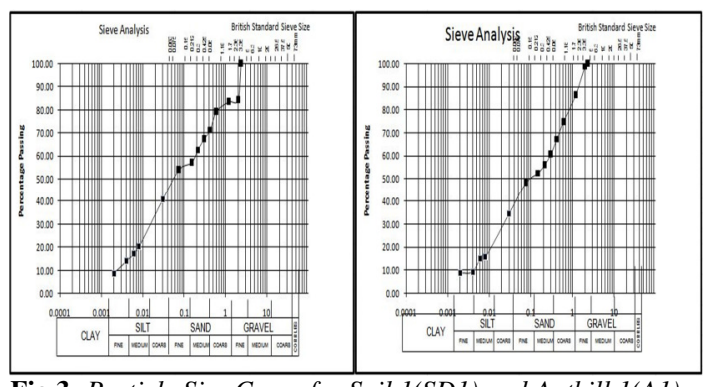

Fig 3: Particle Size Curve for Soil 1(SD1) and Anthill 1(A1)

According to the British standard, B.S. 1377. (1975), if percentage fines are less than $35 \%$, it is adjudged to be a good sub-grade material. The soils of SD1, A1, $\mathrm{A} 2$, and $\mathrm{A} 3$ were below the $35 \%$ fines. The soils are all well graded because their uniformity coefficient, $\mathrm{Cu}$, are all greater than 5. According to AASHTO the soil samples are A-2-6

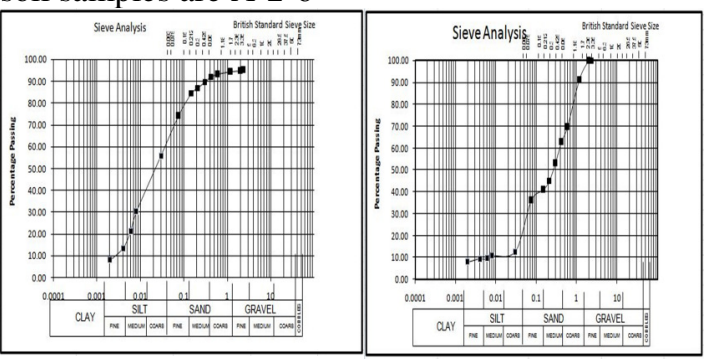

Fig 4: Particle Size Curve for Soil 2(SD2) and Anthill 2(A2)

Gidigasu (1976) stated that a soil is good subgrade if its specific gravity (Gs) range between $2.50-4.60$ and all the samples fell in the range of 2.4-2.6, which indicate that it is a fine grained soil (good subgrade) with fairly high specific gravity mineral and also correlates with the mechanical strength of subgrade (Mesida, 1981). Also, because of narrow range of specific gravity, it's not particularly useful for this evaluation. Values of common properties of laterites are given as: Moisture content (\%) 10-49, Liquid limit (\%) 33-90, Plastic limit (\%) 13-31, Clay fraction $15-40$ Dry unit weight $\left(\mathrm{kN} / \mathrm{m}^{3}\right) 15.2-17.3$ [6]. The Liquid Limit ranges from $36-48.5 \%$ for the red tropical soils and 26.5-33\% for anthill respectively, Plastic Limit value from $19-30.1 \%$ and $19-23 \%$ respectively and Plasticity Index from $15-19 \%$ and $10-12 \%$ respectively.

From the Cassagrande plasticity chart, and particle size distribution, the soils showed more percentage fines than the anthill soils; hence soils are mostly fine grained. According to the USCS, SD1, SD2 SD3 and A1, A2, A3 all fall above the A-line indicating an inorganic clayey material (Casagrande, 1948). From all this, the soil ample and anthills all fell graded (it could either be gap graded or uniformly graded).

intermediate soil with low to medium swelling potentials, giving an indication of well graded soil with clay of no welling property. Hence suitable for subgrade in road construction.

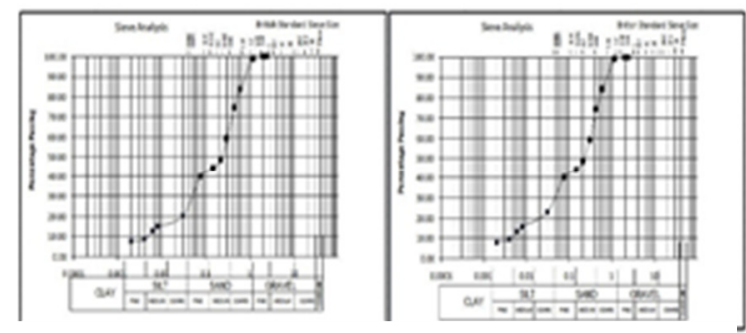

Fig 5: Particle Size Curve for Soil3 (SD3) and Anthill 3(A3)

From the Cassagrande plasticity chart, and particle size distribution, the soils showed more percentage fines than the anthill soils; hence soils are mostly fine grained. According to the USCS, SD1, SD2 SD3 and A1, A2, A3 all fall above the A-line indicating an inorganic clayey material (Casagrande, 1948). From all this, the soil ample and anthills all fell intermediate soil with low to medium swelling potentials, giving an indication of well graded soil with clay of no welling property. Hence suitable for subgrade in road construction.

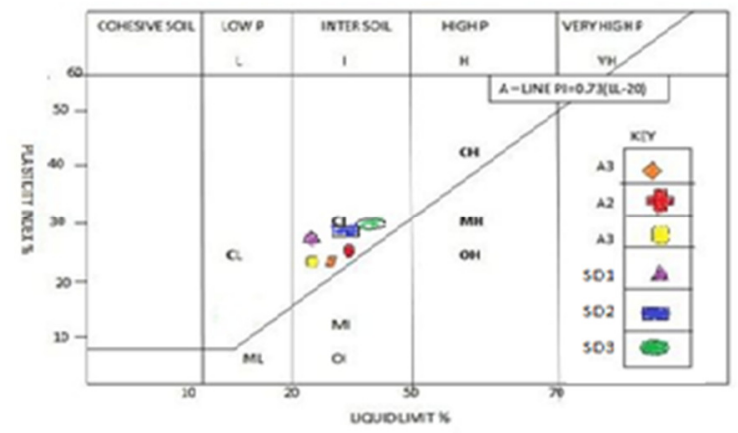

Fig 6: The Cassagrande Plasticity Chart

The OMC of the test samples ranged from 16.5-22.5\% for red tropical soil and $12.5-17.6 \%$ for anthill while MDD fell between $1.5-1.67 \mathrm{~kg} / \mathrm{dm} 3$ and $1.65-1.7 \mathrm{~kg} / \mathrm{dm} 3$ respectively.

All the samples had low OMC to high MDD, and so met the criteria of the Federal Ministry of works but one sample stood out, the red tropical soil of Igarra. The soil sample being well graded on compaction especially on the dry side, the soil forms a grain to grain contact thereby reducing permeability, and porosity which is an indication of suitability of road construction with minimal failures and susceptibility to erosion.The soil 
samples for soaked range from 16-19\%, unsoaked 11$24 \%$ for the red tropical soil while the anthill had 12$24 \%$ for soaked and $24-40 \%$ for unsoaked.

This shows that mechanical strength of the soil is good as a subgrade material because unsoaked conditions are the normal field condition, so that the moulding water content is equal to the equilibrium water content which the soil is likely to attain after construction of pavement. The geotechnical studies have shown that most of the tested soil samples indicate that they contain fines (silt and clay) of $<35 \%$ which is a good engineering characteristic.

Table 1: Particle Size Distribution Silty-Clay Sand

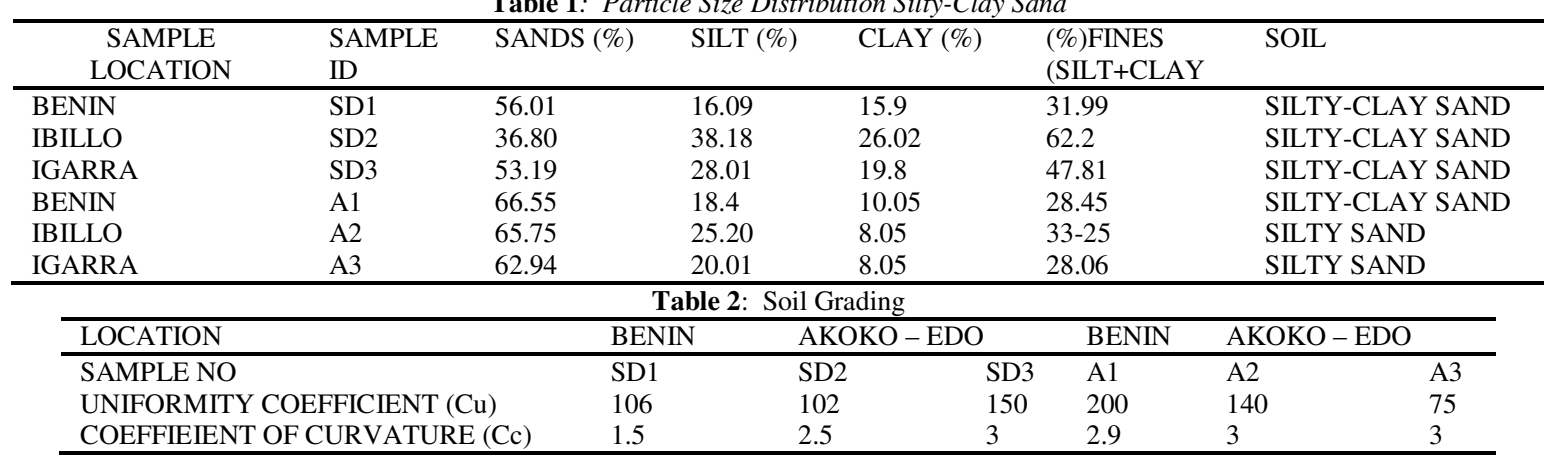

Table 3: Atterberg Limit Results

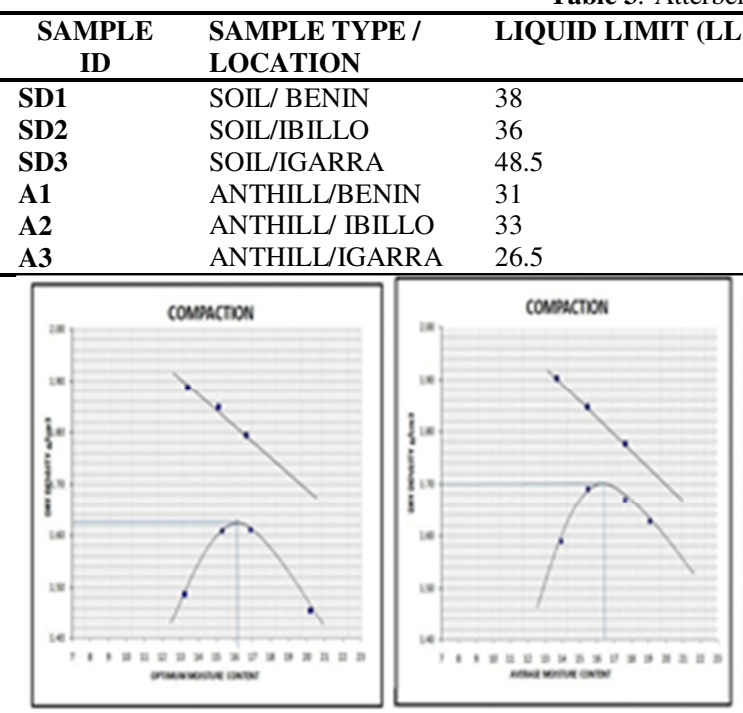

Fig 7: $\quad$ Compaction Curve for Soil 1(SD1) and Anthill 1(A1)
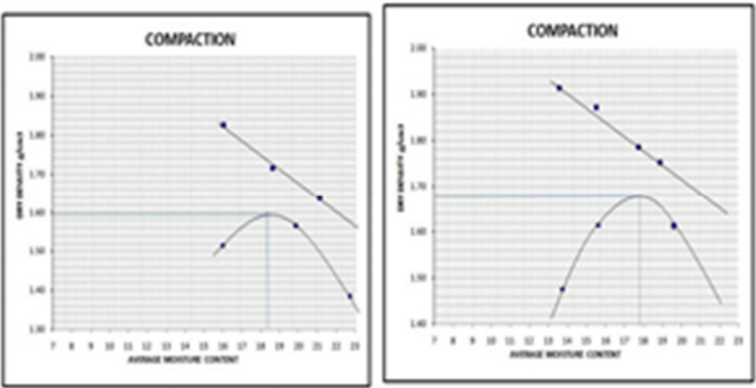

PLASTIC LIMIT (PL)

PLASTICITY INDEX (PI) PI= LL-PI

18.3

15

18.4

$30.1+18$

$23-10$

$15 \quad 11.5$

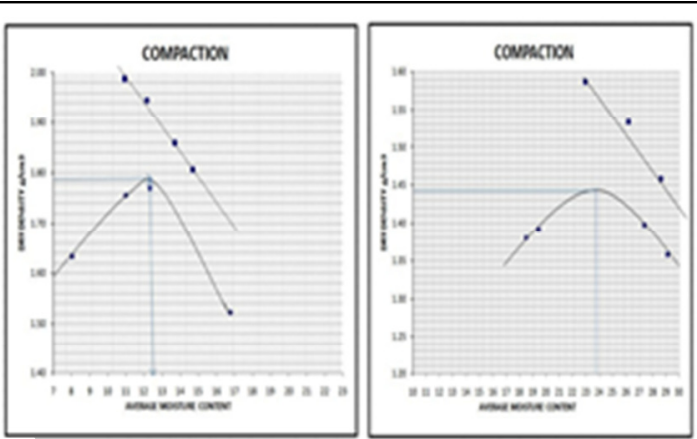

Fig 8: $\quad$ Compaction Curve for Soil 2(SD2) and Anthill 2(A2)

Table 4: Compaction Test Results

\begin{tabular}{cccc}
\hline $\begin{array}{c}\text { Sample } \\
\text { id }\end{array}$ & $\begin{array}{c}\text { Sample } \\
\text { location }\end{array}$ & $\begin{array}{c}\text { Maximum dry } \\
\text { density } \\
\text { (mdd) kg/dm }\end{array}$ & $\begin{array}{c}\text { Optimum } \\
\text { moisture } \\
\text { content (omc) \% }\end{array}$ \\
\hline SD1 & BENIN & 1.58 & 18.5 \\
SD2 & IBILLO & 1.65 & 16.3 \\
SD3 & IGARRA & 1.44 & 23.8 \\
A1 & BENIN & 1.65 & 17.8 \\
A2 & IBILLO & 1.71 & 17.5 \\
A3 & IGARRA & 1.8 & 12.5 \\
\hline
\end{tabular}

Fig 9: $\quad$ Compaction Curve for Soil 3(SD3) and Anthill 3(A3) 
While the plasticity index was $<20 \%$ as the maximum recommended value and fall within the CI group respectively. This implies that the soils have low swelling potential (Low Plasticity) thus making them suitable soil as subgrade material. According to Federal Ministry of Works and Housing (FMWH, 1997), Liquid Limit (LL) is 50\% max, Plastic Limit (PL) is $30 \%$ max, and Plasticity Index (PI) is $20 \%$ maximum for subgrade. All the tested soil samples fall within the stipulated specification. Hence are suitable as subgrade materials. The soils both had high Maximum Dry Density (MDD) and relatively low Optimum Moisture Content (OMC).

Conclusion: The red tropical soils are all good as subgrade materials. This can also be said for the anthills; but depending on the type of the road to be constructed they may have to be stabilized by either mechanical stabilization by compaction or chemical stabilizers such as lime, cement, fly ash, marble dust amongst others to meet the requirement for use as subbase and base material in flexible pavement structures. More work should be carried out on termite hills, not just because they are readily available but it would help to reduce cost of using other stabilizers which are expensive (chemical stabilization) in road construction.

\section{REFERENCES}

Ajibade A.C. (1976). Provisional classification and correlation of the schist belts of the Northwestern Nigeria, Geology of Nigeria, Elizabeth Publishing Co 1143p.

Ajibade A.C; Rahaman M.A; Woakes M. (1987). Proterozoic crustal development in the Pan-African regime of Nigeria. In: Proterozoic Lithospheric evolution (Kroner, Ed). American Geophysical Union. 17: 259-271.

Alayaki, F; Al-Tabbaa, A; Ayotamuno, J. (2015): Defining Niger Delta Soils: Are They Laterites? Civil and Environmental Research www.iiste.org, Vol.7, No.5.

Anon (1990a). Tropical residual soils, Engineering Group Working Party Report. Quarterly Journal of Engineering Geology, 23.

British Standard 1377 (1975). Methods of test for soils for Civil Engineering Purpose. British Standard Institution HMSO London.

Casagrande A, 1948, Classification and Identification of Soils, Transactions, ASCE.

Federal Ministry of Works and Housing. (1997). General specification for roads and Bridges, Vol 2 Federal highway department. FMWH (317p).

Garg, S. K., 2009. Soil Mechanics and Foundation Engineering, 7th ed. Khanna Publishers, New Delhi. 673-683.
Gidigasu, M.D., 1976. Laterite Soil Engineering. Elsevier Scientific Publishing Co., New York.

Lemoguna, Melo U.C; Kamseu E; Tchantra A.B. (2011). Laterite based stabilized products for sustainable building application in tropical countries. Review and Prospects for the case of Cameroon sustainability 3:pp293-305.

Mesida E.A. (1981). Laterites on the Highway Understanding Soil Behaviour. West African Technical Review, November, 1981. Pp 112 - 118.

Millard, R. S. (1993). Road Building in the Tropics (9th ed., p. 312). London, UK: Transport Research Laboratory, State of the Art Review, Hazardous Materials Storage Ordinance Publications.

Northmore K.J; Bell F.J; Martin C. (1996). The Engineering properties and behavior of the brick Earth of South Essex- Quarterly Journal of Engineering Geology and hydrogeology 29(2) 147148.

Nwajide C.S. (2013). Nigeria Sedimentary Basins, CSS bookshops limited, Lagos. pg 321-332.

Odeyemi I.B. (1988). Lithostratigraphic and structural relationships In: P.O. Oluyide, W.C, Mbonu, A.E., Ogezi in the Pre-cambrian Geology of Nigeria. Geological Survey of Nigeria, Kaduna. pp.111-12.

Parkinson, J.A. (1907). The Post Cretaceous Stratigraphy of Southern Nigeria. Quaternary Journal of Geological Society, 63, 311-320.

Rahaman, M.A. (1976). A review of the Basement Geology of Southern Nigeria, Kogbe C.A ed Geology of Nigeria, Elizabeth Co. pp41-58.

Reyment, R.A. (1965). Aspects of the Geology of Nigeria. Ibadan University Press, Ibadan.

Tattam, C.M. (1943). A Review of Nigerian Stratigraphy. Research and Educational Development of the Geological Survey of Nigeria, 26-27.

Vamaguche, K. E. (2003). Iron Isotope composition of Iron oxide as a measure of water rock interaction. An example from Precambrian tropical Laterite in Botsiant. Frontier Research on earth revolution 2. p3. 